released at each synapse, or changes in the number or the properties of postsynaptic receptors. Regardless of the mechanism, the findings of Magee and Cook will challenge our conventional view of how dendrites work and may require us to rewrite some of our current neurophysiology textbooks.

Juan Carlos López

(2) References and links ORIGINAL RESEARCH PAPER Magee, J. C. \& Cook, E. P. Somatic EPSP amplitude is independent of synapse location in hippocampal pyramidal neurons. Nature Neurosci. 3, 895-903 (2000)

NEWS AND VIEWS Spruston, N. Distant synapses raise their voices. Nature Neurosci. 3, 849-851 (2000)

FURTHER READING Stuart, G., Spruston, N. \& Hausser, M. (eds) Dendrites (Oxford Univ. Press, New York, 1999). | Segev, I., Rinzel, J. \& Shepherd, G. M. (eds) The Theoretical Foundation of Dendritic Function (MIT Press, Cambridge, Massachusetts, 1995). WEB SITE J. C. Magee's laboratory

like the first bona fide human pheromone receptor. Using a combination of molecular approaches, they screened a human genomic library and found a sequence $28 \%$ identical to the mouse V1ra2 gene. This sequence, which the authors called V1RL1, contains key amino acid reisdues that are conserved in every rodent pheromone receptor, and is expressed predominantly in the human olfactory mucosa. Further studies will be needed to obtain definitive proof of the function of this receptor in pheromone detection. Hopefully, its ligand will not turn out to be a component of human urine. Juan Carlos López

(2) References and links ORIGINAL RESEARCH PAPERS HOY, T. E., Dulac, C. \& Meister, M. Responses of vomeronasal neurons to natural stimuli. Science $\mathbf{2 8 9}$, 1569-1572 (2000). | Rodriguez, I., Greer, C. A Mok, M. Y. \& Mombaerts, P. A putative pheromone receptor gene expressed in human olfactory mucosa. Nature Genet. 26, 18-19 (2000) REVIEWS Buck, L. B. The molecular architecture of odor and pheromone sensing in mammals. Cell 100, 611-618 (2000). | Dulac, C. Sensory coding of pheromone signals in mammals. Curr. Opin. Neurobiol. 10, 511-518 (2000). | Keverne, E. B. The vomeronasal organ. Science $\mathbf{2 8 6}, 716-720$ (1999)

FURTHER READING Stern, K. \& McClintock, M. C. Regulation of ovulation by human pheromones Nature 392, 177-179 (1998). | Dulac, C. \& Axel, R. A novel family of genes encoding putative pheromone receptors in mammals. Cell $\mathbf{8 3}$, 195-206 (1995)

WEB SITES C. Dulac's Laboratory |M. Meister's Laboratory|P. Mombaerts' Laboratory

VISUAL PERCEPTION

ION CHANNELS

\section{D ID in IT}

Information about three-dimensional shape is important for both grasping and identifying objects. Indeed, in some circumstances, a circular object could be perceived as either a convex ball or a concave bowl with each alternative demanding a different behavioural response. One long-standing question in the field of object recognition is how and where in the brain is information about three-dimensional shape processed? It has been known for some time that the inferior temporal cortex (part of the ventral visual processing stream) plays an important role in object recognition. However, although in the real world most objects are three-dimensional, experimental analysis of the properties of neurons within the inferior temporal cortex have consistently indicated that they seem to be selective for twodimensional form, and for properties such as colour and texture, rather than three-dimensional information.

Three recent papers from Janssen, Vogels and Orban have now identified and started to characterize the properties of a population of neurons within the inferior temporal cortex that respond selectively to three-dimensional shape. Janssen and colleagues capitalized on the fact that the image of an object falls on two slightly different locations on each retina due to the horizontal separation of the two eyes. This phenomenon is called binocular disparity and provides a powerful cue for depth perception. In their experiments, a monocular image was presented to the left and right eye of an awake, behaving rhesus monkey, such that the monkey perceived a three-dimensional shape. They then recorded the activity of single neurons in the inferior temporal cortex while systematically manipulating the stimuli and so characterized the response properties of the neurons in this area of the brain.

Their results indicated that most neurons in the lower bank of the superior temporal sulcus, but not those in more lateral areas of inferior temporal cortex, were selective for three-dimensional shape, despite the fact that neurons in both areas were equally selective for two-dimensional shape. In the latest study, Janssen and colleagues investigated how the neurons represent disparitydefined three-dimensional structure. Their results indicate that most neurons were selective for either first-order disparities (linear variations - an inclined profile sloping toward or away from the subject), or second-order disparities (disparity curvature - concave or convex depth profiles).

Taken together, these studies show three-dimensional shapeselective neurons in the inferior temporal cortex that code concave or convex depth. The ability to encode concave or convex surfaces may provide a robust feature for the object recognition system within the inferior temporal cortex. These new data will surely help to clarify the encoding strategies used by the brain to recognize objects - an area that is hotly debated.

Peter Collins

(D) References and links

ORIGINAL RESEARCH PAPERS Janssen, P., Vogels, R. \& Orban, G. A. Selectivity for 3D shape that reveals distinct areas within macaque inferior temporal cortex. Science $\mathbf{2 8 8}$, 2054-2056 (2000). | Janssen, P., Vogels, R. \& Orban, G. A. Three-dimensional shape coding in inferior temporal cortex. Neuron 27, 385-397 (2000) | Janssen, P., Vogels, R. \& Orban, G. A. Macaque inferior temporal neurons are selective for disparity-defined three-dimensional shapes. Proc. Natl Acad. Sci. USA 96, 8217-8222 (1999)

FURTHER READING Tanaka, K. Curvature in depth for object representation. Neuron 27 195-196 (2000).

\section{O Channel, where art thou?}

The functional impact of a channel is shaped not only by its kinetic properties, but also by its location in the membrane. We have methods to map the spatial distribution of ion channels or to measure their biophysical properties - two approaches that have followed separate paths. But as Korchev et al. report in Nature Cell Biology, the combination of patchclamp and scanning probe microscopy (SPM) is starting to bridge this divide.

In SPM, a pipette is placed within a few nanometres of the cell and moved over the specimen. Current through the pipette depends on the distance between the tip and the membrane. Whenever the pipette moves closer to the cell during the scan, the change in current acts as a signal to restore their original separation. By plotting the three-dimensional displacement of the pipette, a detailed topographic map of the cell surface is obtained.

Korchev et al. combined SPM with patch-clamp recordings to detect ATP-regulated $\mathrm{K}^{+}$channels in cardiac myocytes. Their SPM pipette contained a high $\mathrm{K}^{+}$concentration such that the passage of the tip over an open channel during the scan led to current flow through the membrane, which was recorded by a second pipette - the patch-clamp electrode. By scanning a cell repetitively, they could generate maps that, besides the topographic data, contained information about the position of the channels and how often they were open.

The joint application of SPM and patch-clamp to the study of neurons is a promising development. For example, using this combination of techniques on dendrites should provide insights into the workings of their active conductances, which continue to be largely terra incognita.

$$
\text { Juan Carlos López }
$$

6) References and links ORIGINAL RESEARCH PAPER Korchev, Y. E. et al. Functional localization of single active ion channels on the surface of a living cell. Nature Cell Biol. 2, 616-619 (2000)

FURTHER READING Korchev, Y. E. et al Scanning ion-conductance microscopy of living cells. Biophys. J. 73, 653-658 (1997). 